\title{
PSYCHOLOGICA
}

\section{Avaliação do Autoconceito Infantil}

Autor(es): $\quad$ Loureiro, Manuel Joaquim; Ferrão, Maria Eugénia; Navio, Vera Marisa; Dias, Vera Mónica; Tavares, Adriano; Teles, José

Publicado por: Imprensa da Universidade de Coimbra

URL

persistente:

URI:http://hdl.handle.net/10316.2/3460

DOI:

DOI:http://dx.doi.org/10.14195/1647-8606_52-1_23

Accessed : $\quad$ 26-Apr-2023 12:54:24

A navegação consulta e descarregamento dos títulos inseridos nas Bibliotecas Digitais UC Digitalis, UC Pombalina e UC Impactum, pressupõem a aceitação plena e sem reservas dos Termos e Condições de Uso destas Bibliotecas Digitais, disponíveis em https://digitalis.uc.pt/pt-pt/termos.

Conforme exposto nos referidos Termos e Condições de Uso, o descarregamento de títulos de acesso restrito requer uma licença válida de autorização devendo o utilizador aceder ao(s) documento(s) a partir de um endereço de IP da instituição detentora da supramencionada licença.

Ao utilizador é apenas permitido o descarregamento para uso pessoal, pelo que o emprego do(s) título(s) descarregado(s) para outro fim, designadamente comercial, carece de autorização do respetivo autor ou editor da obra.

Na medida em que todas as obras da UC Digitalis se encontram protegidas pelo Código do Direito de Autor e Direitos Conexos e demais legislação aplicável, toda a cópia, parcial ou total, deste documento, nos casos em que é legalmente admitida, deverá conter ou fazer-se acompanhar por este aviso. 


\section{NÚMERO 52}

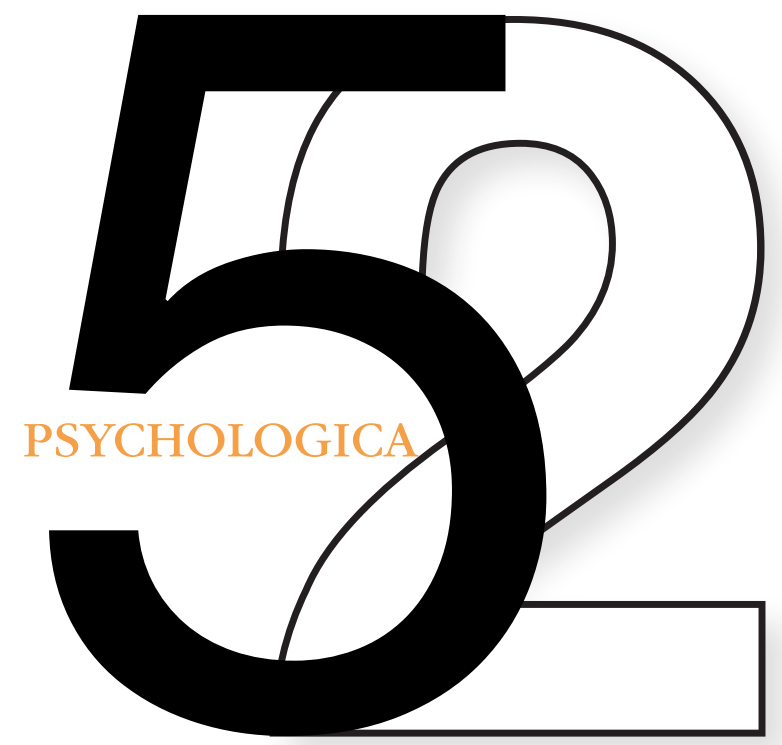

VOLUME I

IMPRENSA DA UNIVERSIDADE DE COIMBRA

FACULDADE DE PSICOLOGIA E DE CIÊNCIAS DA EDUCAÇÃO DA UNIVERSIDADE DE COIMBRA 


\section{Avaliação do Autoconceito Infantil}

Manuel Joaquim Loureiro', Maria Eugénia Ferrão², Vera Marisa Navio², Vera Mónica Dias², Adriano Tavares², José Teles

Percepção do Autoconceito Infantil (PAI) é o nome de um instrumento desenvolvido por Sánchez y Escribano (1999) destinado à avaliação do autoconceito de crianças entre os três e os 10 anos de idade (Pré-primária e $1^{\circ}$ Ciclo do Ensino Básico). Tratase de um instrumento de medida de fácil aplicação e correcção, de aplicação tanto individual como colectiva e, que no seu constructo inclui dez dimensões caracteristicas do auto-conceito infantil. A adaptação portuguesa que agora se apresenta foi desenvolvida no âmbito do Projecto Eficácia Escolar no Ensino da Matemática (3EM), junto de um grupo de 954 alunos do $1^{\circ}$ ciclo do ensino básico que fazem parte de uma amostra constituída na região da Cova da Beira. Os resultados obtidos permitem-nos constatar que esta versão de aplicação colectiva apresenta uma fiabilidade razoável $(K-R 20=0.79)$ e uma estrutura factorial adequada.

PALAVRAS-CHAVE: Autoconceito infantil; Avaliação psicológica.

O interesse pela avaliação e pelo desenvolvimento do autoconceito em contexto educativo tem implícita a ideia de que a sua promoção, ou a dos seus componentes específicos, conduz a melhorias nos resultados académicos e a outros efeitos desejáveis. Com base nesta ideia, encontramos já com alguma frequência actividades transversais de promoção do autoconceito nos planos curriculares de algumas escolas. Em alguns modelos de eficácia escolar, como o de Brookover e Lezotte (1979, referidos por Marsh \& Craven, 1997, p. 131), a maximização do autoconceito académico, da autoconfiança e da realização académica devem figurar entre as principais metas da escola. Inclusivamente, torna-se cada vez mais visível, nas diferentes posições de política educativa, o desenvolvimento de um autoconceito positivo como uma das mais importantes metas da educação.

\footnotetext{
1 Universidade da Beira Interior - Departamento de Psicologia e Educação - loureiro@ubi.pt. 2 Universidade da Beira Interior.
} 
A valorização da promoção do autoconceito decorre da ideia de que um autoconceito positivo e elevado conduz a sentimentos de autoconsideração e de autoaceitação. Por outro lado, a promoção do autoconceito afirma-se ser uma meta educacional desejável, com valor intrínseco. Marsh e Craven (1997), numa revisão da investigação acerca do tema, referem que os dados sugerem que a obtenção de um autoconceito académico positivo influencia aspectos tão importantes como o comportamento académico, as escolhas académicas, o nível de aspiração educacional e a realização académica subsequente.

Assumindo-se, no projecto Eficácia Escolar no Ensino da Matemática, o valor do autoconceito como variável preditiva e também como variável resultado da realização escolar, constatou-se, desde logo, a dificuldade em encontrar um instrumento de medida adequado ao nível etário dos sujeitos que fazem parte da amostra considerada no projecto.

\section{Percepção do Autoconceito Infantil}

A escala de Percepção do Autoconceito Infantil (PAl) é um instrumento desenvolvido por Sánchez e Escribano (1999a, 1999b) destinado à avaliação do autoconceito de crianças entre os 3 e os 9/10 anos de idade (pré-primária e $1 .^{\circ}$ ciclo do ensino básico). A construção deste instrumento, para avaliação do autoconceito infantil, surge da revisão de 26 instrumentos previamente publicados. Perante a necessidade de optar entre um instrumento de auto-avaliação e um instrumento de avaliação inferida pelos adultos, os autores decidem-se claramente pelo primeiro.

O instrumento de medida adoptado é de fácil aplicação e correcção. A aplicação tanto pode ser individual como colectiva; neste último caso, em pequenos grupos de 8 a 10 crianças. As instruções são acessivveis; os 34 itens, de resposta dicotómica, são constituídos por figuras em que algum dos actores, menino ou menina, realiza uma actividade que se pode considerar representativa de um autoconceito positivo ou representativa de um autoconceito negativo. Evitam-se, assim, as limitações de linguagem escrita, típicas das crianças desta idade.

Esta escala compreende um constructo geral composto por 10 dimensões características do autoconceito neste escalão etário da educação infantil e do $1 .{ }^{\circ}$ ciclo do ensino básico:

- autonomia, sentimento de independência;

- segurança (confiança em si mesmo na realização de tarefas);

- desporto e valia na competição;

- família (como se sente na relação com a família); 
- escola/aula, numa actividade há pouco iniciada;

- social (o relacionamento social da criança);

- afectividade (como se sente geralmente [triste, alegre, etc.]);

- autovalorização (sentido de competência própria);

- aspecto físico (aparência física);

- sentimento de posse (de amigos, de objectos, etc.)

Do material da prova faz parte a formulação verbal dos itens a usar pelo aplicador e uma representação pictórica destinada aos sujeitos a ser avaliados. Por exemplo, ao item "Aqui há duas crianças. A uma a sua mãe está a atar os sapatos. A outra está a atá-los sozinha. Que criança se parece mais contigo?" correspondem as figuras 1 e 2 (uma dirigida ao sexo feminino e a outra ao sexo masculino). Nas figuras associadas, em cada item há dois círculos e os sujeitos assinalam um deles; independentemente do item, assinalar o protagonista da esquerda significa autoconceito baixo e assinalar o protagonista da direita significa autoconceito alto.
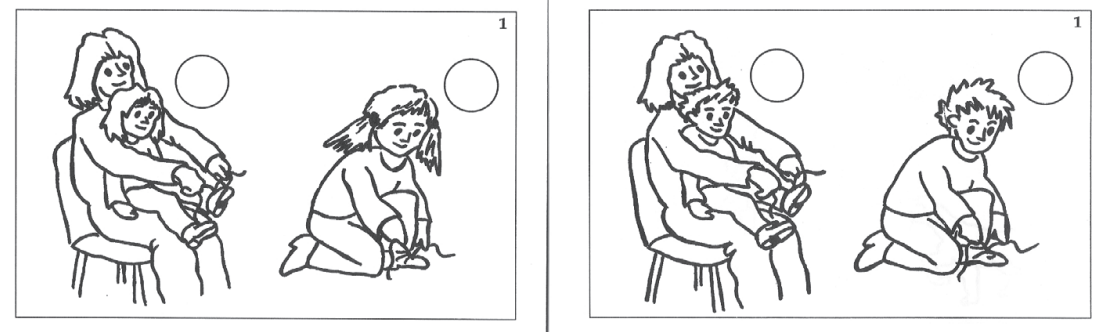

Figuras 1 e 2. Formulação pictórica de um item - a figura da esquerda para as meninas e a figura da direita para os rapazes (Adaptado de Sánchez \& Escribano, 1999a, 1999b)

Os índices apresentados pelos autores Sánchez e Escribano (1999a, 1999b) acerca deste instrumento na versão em língua castelhana atestam as qualidades psicométricas do mesmo. Com efeito, começaram por obter, num estudo experimental com aplicação individual a um grupo de 66 sujeitos, um índice de consistência interna (K-R 20 para dados dicotómicos) de 0,79. Num estudo posterior, numa aplicação colectiva com 200 sujeitos, esse valor ascendeu a 0,87 , e posicionou-se em 0,83 numa aplicação individual com 180 sujeitos. $\mathrm{Na}$ validade por referência a critério, a correlação com a Escala de Autoconceito para Crianças de Martinek-Zaichkowsky (1977) mostrou-se bastante favorável, com um valor de 0,618 ( $p<0,0001)$. Da análise factorial, efectuada para avaliar a dimensionalidade da escala, emergem 12 factores para a forma individual e 13 factores para a forma colectiva. O agrupamento dos itens deixa antever a presença dos elementos considerados no constructo, embora de modo relativamente indiferenciado. 
A adaptação portuguesa que agora se apresenta foi desenvolvida no âmbito do projecto Eficácia Escolar no Ensino da Matemática (3EM), junto de um grupo de alunos do $1 .^{\circ}$ ciclo do ensino básico que fazem parte de uma amostra recolhida na região da Cova da Beira. O presente estudo, indo ao encontro das necessidades do projecto, incide apenas na versão para aplicação colectiva e procura preencher a lacuna que deriva da inexistência deste tipo de instrumentos para o nível etário em causa.

O trabalho de adaptação começou com um estudo piloto destinado a apurar as qualidades dos instrumentos e dos procedimentos a usar no projecto $3 E M$. Fez-se a tradução e a retroversão dos itens, tendo sido empregues os procedimentos habituais na reflexão falada para garantir uma adequada formulação linguística. A a plicação foi efectuada em crianças das oito escolas seleccionadas, que aceitaram colaborar no estudo. Participaram 188 crianças (67 raparigas e 61 rapazes), de oito escolas básicas, oriundas do $1 .^{\circ}$, do $3 .^{\circ}$ e do $5 .^{\circ}$ anos, e com idades compreendidas entre os 6 e os 10 anos de idade. Todos os alunos obtiveram previamente a autorização dos pais. Foram seguidas as normas de aplicação; contudo, não foi possível respeitar o tamanho esperado dos grupos de alunos, que em alguns casos ultrapassou os 10 elementos. Na análise dos itens, encontraram-se vários com correlações bastante baixas com o total da escala e registou-se um alpha (K-R 20, para itens dicotómicos) de 0,66 - portanto, igualmente baixo.

Na análise factorial, foram extraídos 11 factores, com uma percentagem de variância explicada que não varia muito entre eles, responsáveis por $66,79 \%$ do total da variância explicada. Nem todos os factores permitiram uma clara interpretação e alguns deles mostraram-se inter-relacionados. Todavia, há um primeiro factor, que representa o autoconceito académico, relacionado com as actividades da turma, e um segundo relacionado com sentimentos afectivos; os restantes não se diferenciam claramente. Considerando que a aplicação foi efectuada em grupos maiores do que aquilo que é sugerido pelos autores - o que pode ter implicações claras nos resultados - decidiu-se suprimir apenas o item 4, que, para além de uma correlação baixa com o total da escala, se apresentou de difícil compreensão para os sujeitos.

\section{Método: Amostra e Procedimentos}

A amostra de participantes deste trabalho foi obtida no contexto de um projecto de investigação mais amplo, o projecto 3 EM (Ferrão, Loureiro, Simões, Calmão e Guedes, 2005). A população-alvo era constituída pelos alunos do $1 .^{\circ}$, do $2 .^{\circ}$ e do $3 .^{\circ}$ ciclos do ensino básico da região da Cova da Beira (concelhos da Covilhã, do 
Fundão e de Belmonte); a sua distribuição por ciclos era: 3418 (1. ${ }^{\circ}$ ciclo), 1709 (2. ${ }^{\circ}$ ciclo) e 2602 ( $3 .{ }^{\circ}$ ciclo).

No ano lectivo de 2005/06 iniciou-se o seguimento de um cohort (estudo longitudinal) envolvendo os $1 .^{\circ}, 3 .^{\circ}, 5 .^{\circ}, 7 .^{\circ}$ e $8 .^{\circ}$ anos. O processo adoptado na constituição da amostra contempla, em cada um dos ciclos, a estratificação da população por concelho e a amostragem por conglomerados. A selecção das turmas em cada escola fez-se de forma aleatória sistemática, a partir da listagem ordenada das turmas fornecida pelo estabelecimento de ensino.

O estudo teve lugar no ano lectivo de $2005 / 06$ e contou com uma amostra de 942 alunos do ensino básico. Destes alunos, 32,8 \% frequentavam o $1 .{ }^{\circ}$ ano, 34,71\% frequentavam o $3 .^{\circ}$ ano, e $32,5 \%$ frequentavam o $5 .^{\circ}$ ano. Tratou-se de um grupo relativamente equilibrado no que toca à distribuição por sexos, embora se tenha revelado maioritariamente masculino $(53,4 \%)$.

A aplicação foi feita no início do ano lectivo, em sala de aula, e contou com a presença de um professor e de um aplicador previamente treinado. As escolas consideradas no processo de amostragem foram inicialmente contactadas para um adequado planeamento logístico e a participação dos alunos foi previamente autorizada pelos encarregados de educação.

Tendo em conta a apreciação feita a partir do estudo piloto já referido, a aplicação do instrumento foi alvo de cuidados especiais, no sentido de se obter uma recolha de dados nas melhores condições possíveis. No âmbito do projecto $3 E M$, foi elaborado um manual de procedimentos para disponibilizar as orientações técnicas indispensáveis à aplicação correcta dos diferentes instrumentos de avaliação desse projecto, incluindo as provas psicológicas. Este manual contém ainda algumas recomendações para a actuação dos professores intervenientes no processo e apresenta um protocolo para recolha de dados, a preencher por cada aplicador, durante o respectivo processo.

Na formação e recrutamento dos aplicadores foram envolvidos um total de 42 formandos e 7 formadores, das áreas da Psicologia e da Matemática.

As escolas consideradas no processo de amostragem foram previamente contactadas para um adequado planeamento logístico. Após a concordância dos conselhos executivos dos agrupamentos de escolas relativamente à aplicação das diferentes provas, foi também realizada em cada sede de agrupamento uma sessão de sensibilização, com os professores das turmas seleccionadas, para a colaboração no estudo; nomeadamente, para assegurar junto dos encarregados de educação e dos próprios alunos o oportuno intercâmbio de informação. 
Foram garantidas condições de aplicação semelhantes para todos os sujeitos, em cada momento da aplicação, mediante as orientações estipuladas. A sala de aula, sendo um ambiente habitual do aluno, revelou-se o local mais adequado à aplicação. Nas diferentes aplicações, foi pedido ao professor da turma para se manter na sala, no sentido de assegurar um clima disciplinado e orientado para a tarefa, sem, no entanto, fazer qualquer intervenção junto dos alunos, no que diz respeito à execução das provas e ao esclarecimento de dúvidas.

\section{Resultados}

No Quadro 1 podemos observar os resultados obtidos, item a item, ao nível da correlação item-total corrigida. Os índices mostram que, à excepção de quatro itens, todos os restantes apresentam uma correlação superior a 0,21.

No que toca à consistência interna desta escala, o valor alpha (K-R 20) obtido, de 0,79, é claramente adequado.

Com o objectivo de analisar a estrutura dimensional do instrumento, procedemos a uma análise factorial de componentes principais com rotação Varimax. Pretendemos, com este procedimento, averiguar até que ponto aquele nos dá conta de elementos claramente diferenciados do autoconceito infantil.

Quadro 1. Análise dos itens da escala PAI $(n=942)$

\begin{tabular}{cccccc}
\hline Itens & rl-T corr. & Alpha & Itens & rl-T corr. & Alpha \\
\hline 1 & 0,15 & 0,79 & 18 & 0,38 & 0,78 \\
2 & 0,19 & 0,79 & 19 & 0,23 & 0,79 \\
3 & 0,22 & 0,79 & 20 & 0,45 & 0,78 \\
4 & 0,30 & 0,79 & 21 & 0,23 & 0,79 \\
5 & 0,23 & 0,79 & 22 & 0,34 & 0,79 \\
6 & 0,32 & 0,79 & 23 & 0,22 & 0,79 \\
7 & 0,12 & 0,80 & 24 & 0,31 & 0,79 \\
8 & 0,37 & 0,78 & 25 & 0,38 & 0,79 \\
9 & 0,39 & 0,78 & 26 & 0,27 & 0,79 \\
10 & 0,35 & 0,79 & 27 & 0,27 & 0,79 \\
11 & 0,33 & 0,79 & 28 & 0,36 & 0,78 \\
12 & 0,29 & 0,79 & 29 & 0,35 & 0,79 \\
13 & 0,43 & 0,78 & 30 & 0,37 & 0,78 \\
14 & 0,33 & 0,79 & 31 & 0,40 & 0,78 \\
15 & 0,31 & 0,79 & 32 & 0,21 & 0,79 \\
16 & 0,40 & 0,78 & 33 & 0,25 & 0,79 \\
17 & 0,19 & 0,79 & & & \\
\hline
\end{tabular}


Como se pode observar no Quadro 2, esta análise revelou a existência de nove componentes que representam diferentes dimensões da escala PAl e que explicam $48,24 \%$ da variância total.

Quadro 2. Variância total explicada após rotação Varimax.

\begin{tabular}{cccc}
\hline Componentes & Total & \% de Variância & \% Acumulada \\
\hline 1 & 2,692 & 8,156 & 8,156 \\
2 & 2,464 & 7,466 & 15,622 \\
3 & 2,374 & 7,194 & 22,816 \\
4 & 1,757 & 5,324 & 28,140 \\
5 & 1,576 & 4,774 & 32,914 \\
6 & 1,319 & 3,998 & 36,912 \\
7 & 1,308 & 3,963 & 40,875 \\
8 & 1,301 & 3,943 & 44,818 \\
9 & 1,132 & 3,430 & 48,248 \\
\hline
\end{tabular}

Os nove factores emergentes, observáveis na matriz de componentes, não são totalmente diferenciados (ver Anexo). Considerando o nível etário em apreço, é natural que assim aconteça, já que a forma como o sujeito se vê e se aprecia está em pleno desenvolvimento; por essa razão, a expectativa é a de que os aspectos que o definem estejam inter-relacionados e não tão claramente diferenciados como é comum nas idades posteriores. É de contar também com alguns obstáculos inerentes à aplicação de uma prova colectiva nestas idades, devido à dificuldade dos alunos em manter a atenção durante muito tempo seguido.

Da observação da matriz sobressai e existência de três factores com idêntica percentagem de variância explicada e que explicam sozinhos quase metade do total dessa variância. Analisando os itens que constituem o primeiro factor, verificamos que estes traduzem aquilo que poderíamos designar como autoconceito académico, o que revela que a dimensão escolar já é importante nesta idade.

Por sua vez, os itens agrupados em torno do segundo factor mostram que a apreciação que o sujeito faz de si no âmbito da relação social, nomeadamente com os pares, apresenta também alguma consistência. Quanto ao terceiro factor, os itens que se agrupam em torno do mesmo colocam-nos perante o domínio específico da autovalorização e do sentido de competência própria. Os demais aspectos mostram-se inter-relacionados, e a sua diferenciação não é totalmente clara.

\section{Discussão e Conclusão}

Os dados apresentados sugerem que a escala PAI é adequada para obter uma medida válida do autoconceito das crianças. Este é entendido como um todo com- 
posto por aspectos particulares, de que se destacam: o aspecto escolar; a relação social - nomeadamente com os companheiros - e a autovalorização; o sentido de competência própria. Outras dimensões importantes apresentam-se relativamente indiferenciadas, o que é consentâneo com o nível etário destas crianças.

476 Todavia, da nossa experiência de aplicação decorrem algumas recomendações susceptiveis de contribuir para uma maior garantia do desempenho da escala. Antes de mais, respeitar estritamente as condições de aplicação; por exemplo: os grupos não devem ter mais de 10 alunos e a escala não deve ser aplicada em simultâneo com outros testes.

Parece-nos que também valerá a pena fazer uma reflexão acerca da adequabilidade do desenho das figuras, tendo em conta a cultura mediática que rodeia as crianças de hoje.

No mesmo sentido, será oportuno pensar nas actividades reportadas nas figuras, de forma a garantir que estas sejam representativas daquelas que as crianças, nos nossos dias, levam a cabo.

\section{Referências bibliográficas}

Ferrão, E., Loureiro, M. J., Simões, M. F., Calmão, M. J., \& Guedes, P. (2005). Referencial teórico do projecto de investigação eficácia escolar no ensino da Matemática. Covilhã: Universidade da Beira Interior.

Marsh, H. W., \& Craven, R. (1997). Academic self-concept: Beyond the dustbowl. In G. D. Phye (Ed.), Handbook of classroom assessment: Learning, achievement and adjustment (cap. 6). San Diego, CA: Academic Press.

Martinek, T. J., \& Zaichkowsky, L. D. (1977). Manual and scale for the Martinek-Zaichkowsky Self-concept Scale for Children. Jacksonville, IL: Psychologists and Educators.

Sánchez, A. V., \& Escribano, E. A. (1999a). Desarrollo y evaluación del autoconcepto en la edad infantil. Bilbao: Ediciones Mensajero.

Sánchez, A. V., \& Escribano, E. A. (1999b). Medição do autoconceito (C. Murachco, Trad.). São Paulo: Editora da Universidade do Sagrado Coração. 
Anexo

Matriz de componentes após rotação

\begin{tabular}{|c|c|c|c|c|c|c|c|c|c|}
\hline \multirow[b]{2}{*}{ Itens } & \multicolumn{9}{|c|}{ Componentes } \\
\hline & 1 & 2 & 3 & 4 & 5 & 6 & 7 & 8 & 9 \\
\hline $13 \mathrm{Esc}$ & 0,688 & & & & & & & & \\
\hline $20 \mathrm{EsC}$ & 0,656 & & & & & & & & \\
\hline $16 \mathrm{EsC}$ & 0,654 & & & & & & & & \\
\hline 30 Desp & 0,632 & & & & & & & & \\
\hline 9 Desp & 0,509 & & & & & & & & \\
\hline $4 \mathrm{Soc}$ & & 0,727 & & & & & & & \\
\hline $11 \mathrm{Soc}$ & & 0,693 & & & & & & & \\
\hline 29 Soc & & 0,679 & & & & & & & \\
\hline $18 \mathrm{Soc}$ & & 0,589 & & & & 0,356 & & & \\
\hline 12 Emo & & 0,433 & & & & & & & \\
\hline $2 \mathrm{Soc}$ & & 0,391 & & & & & 0,373 & & \\
\hline $19 \mathrm{Val}$ & & & 0,652 & & & & & & \\
\hline 27 Val & & & 0,533 & & & & & & \\
\hline $31 \mathrm{Val}$ & & & 0,529 & 0,352 & & & & & \\
\hline $14 \mathrm{Val}$ & & & 0,508 & & & & & & \\
\hline $25 \mathrm{Esc}$ & & & 0,498 & & & & & & \\
\hline $10 \mathrm{Val}$ & & & 0,452 & & & & & & \\
\hline $21 \mathrm{Val}$ & & & 0,406 & & & & & & \\
\hline $5 ?$ & & & & & & & & & \\
\hline 28 Conf & & & & 0,615 & & & & & \\
\hline $22 \mathrm{Emo}$ & & & & 0,611 & & & & & \\
\hline 24 Conf & & & & 0,397 & & & $-0,375$ & & \\
\hline 23 Aut & & & & & 0,698 & & & & \\
\hline 1 Aut & & & & & 0,647 & & & & \\
\hline $8 \mathrm{Esc}$ & & & & & & 0,599 & & & \\
\hline 15 Pos & & & & 0,439 & & 0,454 & & & \\
\hline 17 Pos & & & & & & 0,433 & 0,358 & & \\
\hline 26 Pos & & & & & & & 0,620 & & \\
\hline 32 Asp & & & & & & & & 0,807 & \\
\hline 6 Desp & 0,356 & & & & & & & 0,450 & \\
\hline 3 Emo & & & & & & & & & 0,679 \\
\hline 7 Fam & & & & & & & & & 0,620 \\
\hline $33 ?$ & & & & & & & & & \\
\hline
\end{tabular}

Nota: método de extracção - componentes principais com rotação Varimax com normalização de Kaiser.

Legenda: «Esc» - escola (actividades na aula); «Desp» — desporto e valia na competição; "Rel» - relacionamento social com os pares; "Emo" - afectividade (como se sente geralmente); "Val» - autovalorização (sentido de competência própria); "Conf» - confiança em si mesmo na realização das tarefas, segurança; "Aut» - autonomia, sentimento de independência; "Pos» - sentimento de posse (de amigos, de objectos, etc.); "Asp» aspecto físico (aparência física); "Fam» — família. 


\section{Children Self-Concept Evaluation}

Children Perception of Self-Concept is the name of an instrument developed by Sánchez and Escribano (1999) designed to evaluate self-concept of children with ages between 3 and 10 years (pre-primary and first level of basics). It's a measure instrument of easy administration and scoring, suitable for individual and collective application. In its construct includes ten characteristic dimensions of children self-concept. The Portuguese adaptation presented here was developed in the context of the School Efficacy in Mathematics Teaching Project, with a sample of 954 students in the first level of basics from Cova da Beira region. The results show that this instrument of collective administration has a reasonable reliability (K-R $20=0.79)$ and an adequate factor structure.

KEY-WORDS: Children self-concept; Psychological evaluation.

\section{Evaluacion de L'auto-Concept Infantile}

Perception de L'Auto-Concept Infantile (PAI), est comment s'appelle l'instrument développé par Sánchez et Escribano (1999) destiné à évaluer l'auto-concept des enfants âgés entre les trois et les dix ans (Enseignement Pré-Primaire et École Primaire). Il s'agit d'un instrument de mesure, autant facile d'appliquer que de corriger, soit individuel soit collectif, et qui présente dix dimensions caractéristiques de l'auto-concept de l'enfant. L'adaptation portugaise ici présenté a été développé au contour du Projet Efficace Scolaire à l'Enseignement de la Mathématique (3EM) avec 954 étudiants du premier cycle de l'enseignement primaire qui composent l'échantillon construite à la région Cova da Beira. On constate avec les résultats obtenus que cette version au niveau de l'application collective présente une fiabilité raisonnable $(\mathrm{K}-\mathrm{R} 20=0.79)$ bien qu'une structure factorielle approprié.

MOTS-CLÉS: Auto-concept Infantile, Évaluation psychologique de l'enfant. 